\title{
Evolution and Composition of the Traditional Timber Structure Column Bases in the Southern Region of China - A Case Study of Shaoxing City
}

\author{
Zhou Xinmo, Wang Wei*, Zhou Ke and Chen Wenping \\ School of Civil Engineering, Shaoxing University, Shaoxing 312000, China
}

\begin{abstract}
As a very unique structural component of traditional timber architecture, column base is a natural combination of stone carving technology and timber structure system, from which we can understand the broad and profound traditional architectural culture. In This paper, the emergence and evolution of the column bases art history was firstly described to analyze the factors that promote the development and changes of column bases. Moreover, Finally, the dimension of column bases was introduced. The results of this paper can be taken as the reference for the development of the antique buildings and the new Chinese architecture.
\end{abstract}

Keywords: Column base, composition, timber structure, evolution.

\section{INTRODUCTION}

Chinese traditional timber structure is a unique architecture with timber frame connected by tenons. It has three sections model since ancient times: upper part above the beam, middle part above the ground and lower part under the ground. The continuity and diversity of development of each part or each component of this architectural model reflects the cultural style and technical characteristics of historical periods in that region. Column bases are located under the column and above the ground as a structural component which can connect the middle and lower part with the following functions: (1) prevent timber architecture from moisture; (2) protect the column feet from damage; (3) increase the contact surface area between the column and the ground and reduce the pressure to prevent it sinking; (4) improve the seismic performance of timber-framed buildings by making use of slippage between the column and bases. In addition, we can distinguish the era, grade, and craftwork of buildings according to the different shape of the column bases [1-5].

Shaoxing is a typical traditional Canal Town in Southern China with interleaving rivers, where the houses are built by the river. Architecture and river are closely connected, thus the stone column bases are necessary to be set under the column to avoid moisture. Column bases with diverse forms are widely used. There are a lot of researches on Shaoxing traditional architecture techniques, such as Shaoxing Taimen, casement window of Shaoxing residence, opera stage with relative research literature, but fewer researches on the local column bases. As can be seen from the existing literatures, the study on the evolution and characteristic of ancient building's column bases in Shanxi has been conducted [1], moreover, the mechanism of sliding friction shock isolation between timber column and plinth in historical buildings the

*Address correspondence to this author at the No. 508, West Ring Road, Shaoxing, China. 312000; Tel: 18367512859; E-mail: wangwells@qq.com also has been studied [2]. Through the study on evolution and composition of Shaoxing traditional architecture column bases, it is aimed at succeeding the traditional technology and artistic achievements, providing reference and basis for the protection and repair of traditional architecture and the antique architectural design.

\section{EVOLUTION OF COLUMN BASES OF TIM- BER COLUMN}

\subsection{Background}

The emergence of column base is derived from the wooden column development. It was called as the column base in the Song Dynasty (A. D. 960-A. D. 1279) and capital stone in the Qing Dynasty (A. D. 1636-A. D. 1911).

Column base is one of structural components in the timber structural houses. In the early period, the columns are directly buried under the ground to prevent it from sinking down by paving stones at the bottom. Afterwards, the timber columns buried under the ground are easily decayed and damped, so both of the stones at the bottom and the columns are raised to the ground. The space between the base and the column is often put with some substance to prevent moisture penetrating from the base to the column, and these substances are called as "Zhi". It is the formation process of the column bases which has provided a thorough foundation for the development of column bases in history [6].

\subsection{Technical Evolution}

There are 4 stages of the development of traditional architecture column bases:

(1) Pebble stage, that is paving the pebble at the bottom of the column and tamping it, as shown in Fig. (1);

(2) Boulder stage, that is paving boulder at the bottom of the column, but boulders and the column foot are still buried underground, as shown in Fig. (2); 


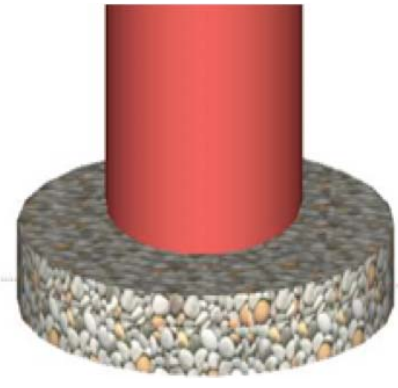

Fig. (1). Pebble stage.

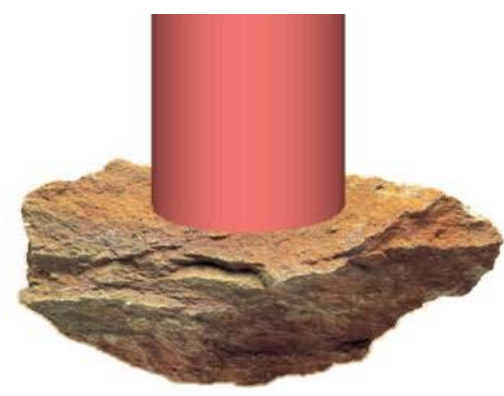

Fig. (2). Boulder stage.

(3) Ground stage, that is raising the column base to the ground but with simpler form and no decoration, as shown in Fig. (3);
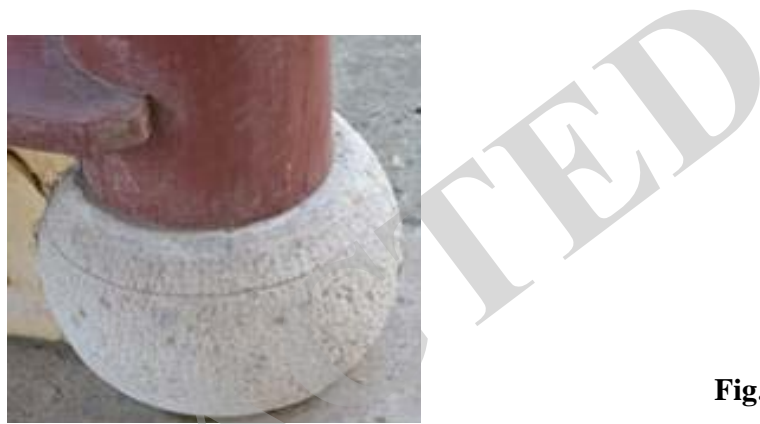

(B. C. 2100-B. C. 221) to the Qing Dynasty ( B. C. 221-B. C. 207) have received the baptism of different cultural ethos. Craft and cultural connotations of column bases are also changed with the times alternation.

Pebbles are applied to most of the column bases in the Pre-Qin Dynasty (B. C. 2100-B. C. 221). While in the Qin Dynasty (B. C. 221-B. C. 207), boulder stones are taken as the column bases. To the Han Dynasty (B. C. 202-A. D. 220), column bases are with very simple styles such as Fupen (as shown in Fig. 5) style or Fudou (as shown in Fig. 6) style.

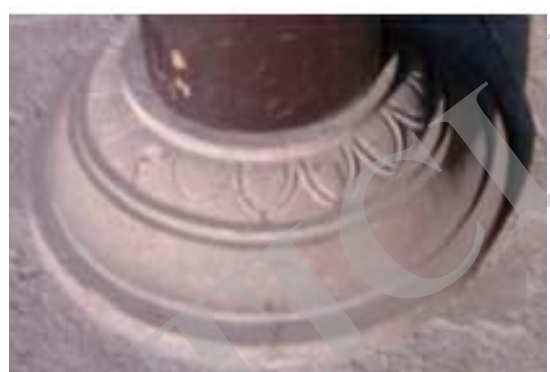

Fig. (5). Fupen column bases with petals decoration.

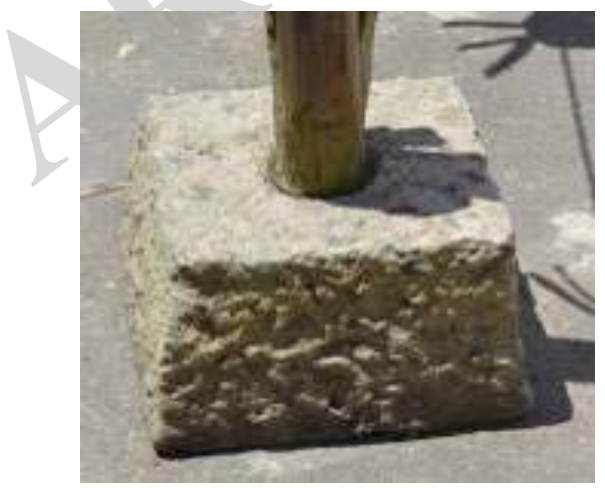

Fig. (6). Fudou column bases.

To the Six Dynasties (A. D. 229-A. D. 589), there are column bases with character style, lion beast style and petals style. When Buddhism is introduced to central plains in Six Dynasties (A. D. 229-A. D. 589), it has formed its own unique styling with the influence of Buddhism by using petals decoration.

To the Song Dynasty (A. D. 960-A. D. 1279), column bases have richer design with a special introduction of the form, proportion and decorative techniques in "Yingzao Fashi". To the Yuan Dynasty (A. D. 1271-A. D. 1368), central plains by the domination of steppe peoples with bold and uninhibited character determine the column bases with simple carvings.

On the basis of the Yuan Dynasty (A. D. 1271-A. D. 1368), in the Ming Dynasty (A. D. 1368-A. D. 1644), column bases are with simple form carvings and styling. Today, the most common cylindrical and drum-shaped column bases (Fig. 7 and Fig. 8) are popular styles of column bases in the early Qing Dynasty (A. D. 1644-A. D. 1775) [1, 7]. By the Mid-Qing Dynasty (A. D. 1776-A. D. 1839), carving arts appear in large numbers of column bases and also push the sculpture art to the gorgeous peak. 


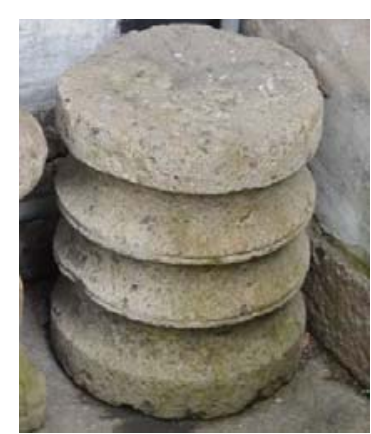

Fig. (7). Cylindrical bases.

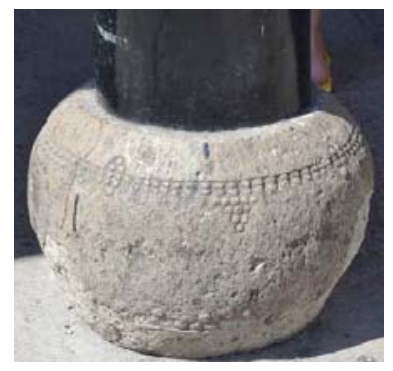

Fig. (8). Drum-shaped column bases.

Today, in many antique buildings, we still can see a variety of column bases. Just observe carefully you can find the column bases everywhere are different from the shape or carved texture. But no matter what kind, the forms tend to be simple and plain or even just a simple geometric shape.

\section{COMPOSITIONS OF COLUMN BASES OF TIMBER COLUMN}

\subsection{Overview}

Shaoxing City has a long history which was built in 490 BC. Among many famous and ancient cities, it is rare to find out another one as Shaoxing being constant since founding.

With the development of history, the column bases form change with each dynasties alternation. Shaoxing is an ancient city with ancient historic buildings, so the forms of column bases are different. However, because Shaoxing is not the political center of ancient dynasties, the column bases forms remain to be simple and plain.

There are two main origins of column bases of Shaoxing traditional architecture. One is column base in the ancient buildings most of which are Qing Dynasty (A. D. 1616-A. D. 1911) architecture and also the Republic of China (A. D. 1912-A. D. 1949) architecture and these kinds of column bases reflect the historical characteristics of that time. The other is column base in modern antique architecture which absorbs the essence part of the form and carving of column bases of ancient architecture, and can be used as reference for antique buildings construction.

\subsection{Main Compositions}

Column bases are in different styles with no specific structure. However, except for some special column bases, by analysis of column bases from the most traditional architectural forms, the column bases structure can be summarized as base top, base body and the base end, as shown in this is the most common form of column bases in Shaoxing traditional buildings. While with different sizes in different regions, column bases forms may be various but remain essentially the same despite all apparent changes.

\section{(1) Base top}

The base top is the part with the function of transitional connection of the column top with column body and load bearing. Due to its location and angle, it is easy to be seen by people. With small size, it is smaller than the column bases without any ornamentation in order to serve the base body. The connection between base top and the column have the following three ways as shown in Fig. (10): 1) insert the column with pins into the "Haiyan" on the top center of the column; 2) make the top column as a Taoding to fix the column; 3) polish the base top surface smooth and put the column on it. Since the top of the column polished like a mirror, it is also known as "drum mirror". By polishing the top surface of the column bases can reduce the coefficient of friction between the column and column bases. Therefore, in the event of earthquakes or high winds, it can play the role of shock insulation [8].

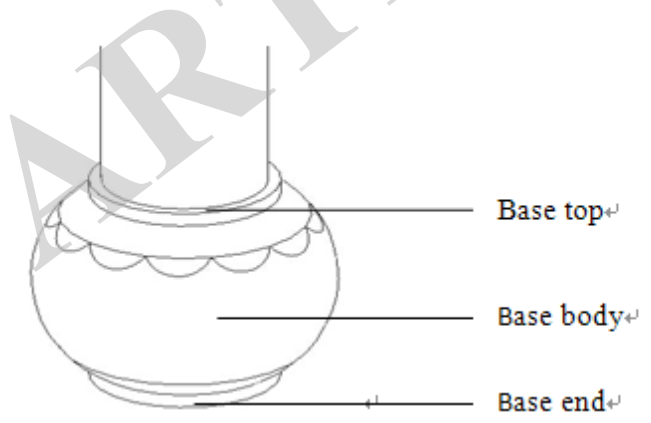

Fig. (9). The composition of the column base.

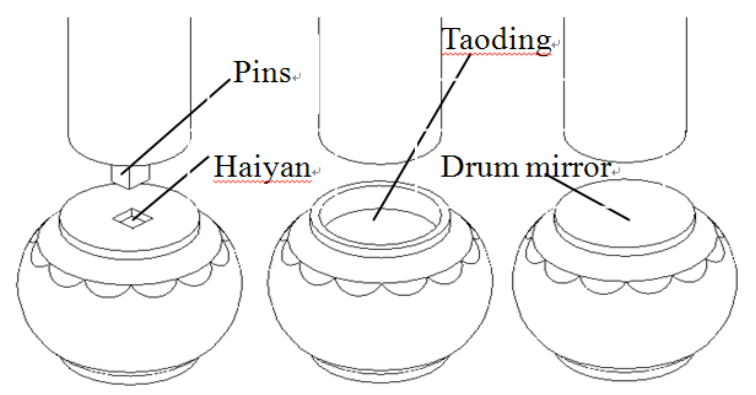

Fig. (10). Connections between base top and column.

In the contact area of drum mirror and the column, it is also with two kinds: with Zhi or without Zhi. It was wrote in "Chinese architectural art gallery - column bases chapter" by Liang Sicheng [9], "column bases roughly can be divided into two parts: the upper part which bears the column pressure is the column base; the plate disk between the column and base is Zhi. It has two approaches: column bases without Zhi (Fig. 11) and column bases with Zhi (Fig. 12)". Zhi is generally made from stone or wood. It is extension and strengthens on the base functions. Besides stone Zhi, the wood Zhi also can effectively prevent the column foot from moisture. The reason is that the grain of Zhi is transverse direction which can effectively prevent water rising along the grains. If decayed, Zhi can be partially replaced without 
affecting the overall structure of the whole column. Zhi can also be placed under the column when the column foot is damaged. In short, there are a lot of benefits of Zhi, but its own role is complementary to the column bases moisture proof function. In the region with drought climate, the column foot moisture proof requirements are not so high, so the bases with Zhi is rare in the north area while in rainy and humid south area it is relatively common. But in Shaoxing area, it is not common.

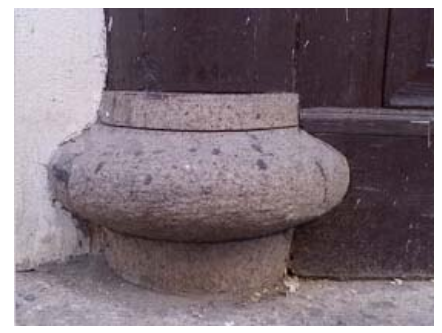

Fig. (11). Column bases without Zhi.

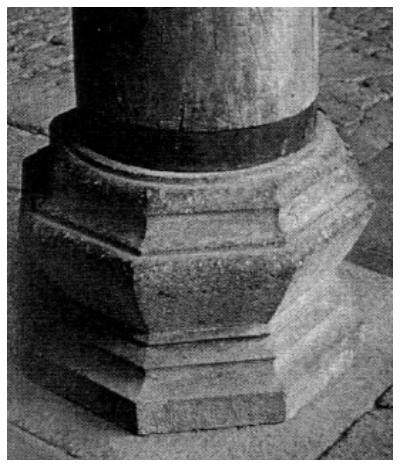

Fig. (12). Column bases with Zhi.

(2) Base body.

The base body is the column base we can directly see, also known as stone capitals or drum step. The base body of Shaoxing traditional timber architecture is mostly round drum shape as shown in Fig. (9), in which the drum diameter is greater than the column diameter. This approach has the following advantages: (1) "Drums" has auspicious and festive meaning which can reflect people's good wishes for life; (2) Because the drum diameter is greater than the column diameter, it can make the structure more stable; (3) The convex drum makes base body and column bases and wall studs are not on the same plane which can avoid some external impact damage to the column or walls; (4) Prevent ground moisture to the column feet along the base body; (5) The convex drum can protect the column feet by making the accumulation of rainwater dripping down; (6) The up and down grooves can prevent water droplets and moisture as well.

Among them, the action principle of (4), (5) and (6) are similar to the windowsill dripping practice by increasing the difficulty of the lower water moving upward, meanwhile accelerating the droplets falling to the lower part, thus from the three levels preventing column feet from corrosion.

\section{(3) Base end.}

As shown in Fig. (9), the base end is the contraction part under the bottom of the base body to stand out the protruding section of the base body. It is the bottom part which contacts with the ground and transfers load to the ground. Generally the shape is consistent with the base body but not absolute, for example the base ends of hexagonal, octagon column base often are round shape.

\subsection{Size and Dimensions}

Song Dynasty (A. D. 960-A. D. 1279), "Yingzao Fashi" has a standardization of size and dimension of the column bases: the side length of the square column bases is equal to twice the diameter of the column. For example, column diameter is $20 \mathrm{~cm}$, and side length of square column bases is $40 \mathrm{~cm}$. If the side length of column bases is less than 1.4 Chinese Chi, the height should be designed according to 0.8 Chinese Chi per Chinese Chi of the edge length; if the side length of column bases is more than three Chinese Chi, the height is equal to half of the side length [10].

It should be noted that one meter is equal 3 Chinese Chi, and one Chinese Chi is equal 10 Chinese Cun.

Nowadays, most of Shaoxing traditional buildings architecture is a continuation of the Qing Dynasty buildings architecture. The column bases specifications introduced in the Qing Dynasty "Gongcheng Zuofa Zeli" is especially for the column base specifications. There are two types, namely small building and large building.

For small building, the diameter of the column base should be equal to 2 times the column diameter minus 0.2 Chinese Chi, and the height of the column base should be designed as 1/3 column base diameter. For large building, the diameter of the column base should be equal to 2 times the column diameter, and the height of the column base should be designed as $1 / 2$ column base diameter.

As shown in Fig. (13), the dimension of a lotus Fupen style column bases which is taken from West Park.

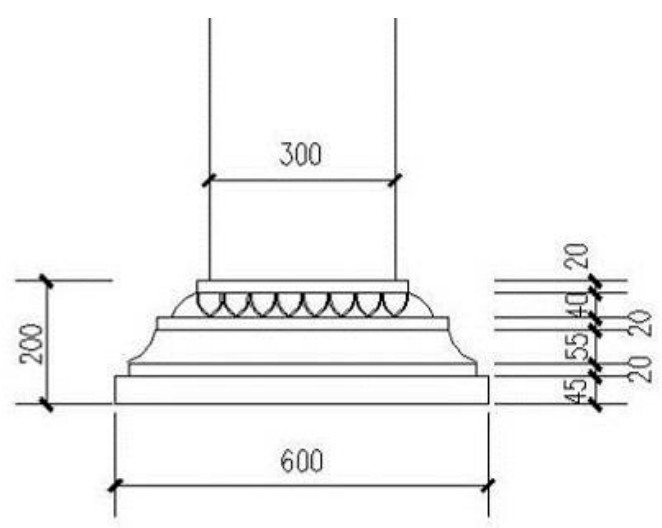

Fig. (13). Size and dimensions of the column bases (mm).

The origin and dimension of the column bases taken from Shaoxing are listed in Table 1. From here we can find that column bases of Shaoxing traditional architecture, in addition to Fupen style which complies with standards of "Yingzao Fashi" and "Engineering Rules", the rest types is almost with the same height and diameter of the column base. 
Table 1. Origin and dimensions of column bases.

\begin{tabular}{|c|c|c|c|}
\hline No. & Figure & Origin & Height and diameter $/(\mathbf{m m} \times \mathbf{m m})$ \\
\hline \hline 1 & Figure 1 & Drawn by the author & $250 \times 210$ \\
\hline 2 & Figure 2 & Drawn by the author & $250 \times 250$ \\
\hline 3 & Figure 3 & Longtan temple, Jianhu Lake & $200 \times 600$ \\
\hline 4 & Figure 4 & Sanjiang taimen, Doumen village & $300 \times 300$ \\
\hline 5 & Figure 5 & West Park & $350 \times 200$ \\
\hline 6 & Figure 6 & No. 68 residence, Fanjiang village & $260 \times 250$ \\
\hline 7 & Figure 7 & Lu Xun's former residence & - \\
\hline 8 & Figure 8 & Luoshi residence, Shangxiang village & \\
\hline 9 & Figure 9 & Drawn by the author & $300 \times 280$ \\
\hline 10 & Figure 10 & Drawn by the author & - \\
\hline 11 & Figure 11 & CangqiaoZhijie residence, Shaoxing & $200 \times 600$ \\
\hline 13 & Figure 12 & The Complete Works of Chinese Fine Arts Category & \\
\hline
\end{tabular}

\section{CONCLUSION AND DISCUSSION}

Shaoxing traditional architecture in the forms of the column bases are with rich creativity, clean lines without many decorations. From the analysis of the historical process of Shaoxing region, we can find that: since Dayu Flood Control in Xia Dynasty, Shaoxing has only become the capital of Yue Kingdom, then as the state of various dynasties, so the development of its various aspects is slower than the political and economic center of the region with high-tech carving. People specialized on this field is few so that can not play to their creativity in terms of carving, thus mainly focus instead on making column bases simple and convenient modeling. Thus are various forms of column bases we can see nowadays.

Column base is only one kind of Shaoxing traditional building components, although the function is very important in the whole building, because set in the bottom of the column, it is always ignored by people who will always look forward or upward. In order to be able to appreciate a thing down head, it must make people understand its value.

\section{CONFLICT OF INTEREST}

The authors confirm that this article content has no conflict of interest.

\section{ACKNOWLEDGEMENTS}

The authors thank the reviewers who gave a thorough and careful reading to the original manuscript. Their comments are greatly appreciated and have help to improve the quality of this paper. This research is partly supported by the Bureau of Shaoxing Urban Planing, and by the college student research foundation of Shaoxing University.

\section{REFERENCES}

[1] Y. P. Chang, Q.C. Zheng, "The evolution and characteristic of ancient building's column bases". Traditional Chinese Architecture and Gardens, no. 1, pp. 26-29, 2008.

[2] K. Yao, and H. T. Zhao, "Study on the mechanism of sliding friction shock isolation between timber column and plinth in historical buildings", Engineering Mechanics, vol. 23, no.8, pp.127131, 2006.

[3] Krishnamurthy Natarajan and Thambiratnam David P. "Finite element analysis of column base plates", Computers and Structures, vol. 34, no.2, pp. 215-223, 1990.

[4] S. Khodaie, M. R. Mohamadi-shooreh, and M. Mofid, "Parametric analyses on the initial stiffness of the SHS column base plate connections using FEM", Engineering Structures, vol. 34, pp. 363-370, 2012.

[5] Takamatsu Takao, Tamai Hiroyuki1, Yamanishi Teruaki and Matsuo Akira. "Self-centering performance of non-slip-type exposed column base", Proceedings of the 5th International Conference on Behaviour of Steel Structures in Seismic Areas Stessa, pp. 357-362, 2006.

[6] G. Y. Zhu, "Graphic traditional residential architecture and decoration”, Beijing: China Machine Press, pp. 96-101, 2011.

[7] Gomez, Ivan R., Kanvinde, Amit and Deierlein Gregory, et al. "Experimental investigation of shear transfer in exposed column base connections", Engineering Journal, vol. 48, no.4, pp.357$362,2011$.

[8] H. Q. Li "Chinese traditional architectural structure", Beijing: Peking University Press, pp.107-108, 2010.

[9] S.C. Liang "Chinese architectural art gallery", Tianjin: Baihua Literature and Art Publishing House, pp.317-324, 199).

[10] Li J (Dynasty Song). "Ying zao fa shi": Shanghai: Shangwu YinShu Kuan, pp.21-22, 1950. 